\title{
Viver em áreas de risco: tensões entre gestão de desastres ambientais e os sentidos de risco no cotidiano
}

\author{
Living in areas of risk: tensions between management of \\ environmental disasters and the significance of risk in everyday life
}

${ }^{1}$ Psicologia Social, Pontifícia Universidade Católica de São Paulo. R. Monte Alegre 984, Perdizes. 05.014901 São Paulo SP Brasil. mjspink@pucsp.br

\begin{abstract}
This paper addresses risks management of environmental disasters from the standpoint of people in vulnerable situations. It is based on the initial phase of research on Life in risk areas conducted with financial support from CNPq. Data was gathered from multiple sources: activities of a local organization (Sociedade Santos Mártires); informal conversations with community residents and leaders in the region; legislative history of $\mathrm{Bra}$ zilian civil defense; newspaper articles on disasters in the region and extensive bibliographic research. Based on social of critical analysis of risk theories, the objective was to understand the processes of how people deal with risk. Three themes are addressed: description of the territory focusing on the concept of social and environmental vulnerability; the complex network of actors that constitute risk in this territory; local risk management with a focus on everyday life in the community. The preliminary results suggest that in order to understand risk management in situations of vulnerability it is necessary to take into account the heterogeneous network of actors that constitute risk in the territory as well as the multiple dimensions of risk hierarchies as perceived by local inhabitants.
\end{abstract}

Key-words Risks, Vulnerabilities, Landslides, Civil defense, Production of significance, Psychosocial processes.
Resumo Este artigo aborda a gestão dos riscos de desastres ambientais na ótica de pessoas em situações de vulnerabilidade. Tem por base as etapas iniciais da pesquisa Viver em área de risco, desenvolvida com o apoio do CNPq. As informações derivam de múltiplas fontes: atividades de uma organização local (Sociedade Santos Mártires); conversas informais com moradores e lideranças comunitárias da região; histórico das legislações sobre a defesa civil brasileira; matérias de jornais sobre desastres na região e extensa revisão bibliográfica sobre o tema. Apoiada em vertentes críticas das teorias sociais de risco, o objetivo é entender os processos por meio dos quais os atores dão sentido aos riscos. São abordados três tópicos: a descrição do território, com foco no conceito de vulnerabilidade socioambiental; a rede complexa de atores que performam risco naquele território; a gestão dos riscos por parte de pessoas com foco na vida cotidiana da comunidade. Os resultados preliminares sugerem que para entender a gestão dos riscos, na perspectiva das pessoas em situação de vulnerabilidade, é necessário caracterizar a rede heterogênea de atores que performam o risco nesse território, assim como as múltiplas dimensões da hierarquização desses riscos por parte dos moradores.

Palavras-chave Riscos, Vulnerabilidades, Escorregamentos, Defesa civil, Produção de sentidos, Processos psicossociais 


\section{Introdução}

A relação entre as condições de vida e a saúde da população tem longa história. Se tomarmos Michel Foucault ${ }^{1}$ por guia, seu relato sobre o nascimento da medicina social nos dá valiosas pistas sobre intervenções urbanas como estratégias de governamentalidade que têm por foco a saúde da população. Seja no enquadre da medicina urbana francesa, com ênfase na disposição dos equipamentos no território, seja na medicina sanitária inglesa, essas intervenções tiveram consequências positivas no que concerne à diminuição de certos agravos à saúde relacionados à qualidade das moradias, ao acesso à água potável e às soluções de engenharia para tratamento das águas servidas e do esgoto.

Porém, as soluções de engenharia associadas à saúde pública são hoje dificultadas pela interação entre intervenções antrópicas no ambiente, decorrentes dos processos de desenvolvimento socioeconômico, com consequente expansão do ambiente construído e a exacerbação de certos eventos climáticos. Há na literatura uma diversidade de análises sobre a relação recíproca e multifacetada entre desenvolvimento e desastres, que em certos aspectos determina a vulnerabilidade das pessoas $^{2}$. Um dos exemplos citados para ilustrar essa relação é o das enchentes, sendo que a estimativa é de que o número de pessoas que vivem em risco de enchentes devastadoras no mundo passará de um bilhão, contabilizado em 2004, para dois bilhões em $2050^{2}$. Essa previsão tornase mais impactante quando consideramos que a expansão do ambiente construído está intrinsecamente relacionada às dinâmicas de pobreza e exclusão social, com as populações mais pobres ocupando as áreas de maior risco de inundações e deslizamentos. Dados do International Strategy for Disaster Reduction - ISDR, das Nações Unidas, publicados em 2009, indicam que atualmente as enchentes atingem cerca de 102 milhões de pessoas por ano e, a maior parte das pessoas expostas (95\%) e dos óbitos (95\%), se encontra nos países com menos renda per capita ${ }^{3}$. É nesse enquadre que cabe abordar a gestão de riscos ambientais a partir da noção de vulnerabilidade socioambiental ${ }^{4,5}$.

Obviamente, nas circunstâncias atuais, intervenções como as que matizaram a medicina social, a que Foucault se referia, nem sempre são adequadas. Como aponta Norberto Bobbio ${ }^{6}$, vivemos atualmente na era dos direitos e soluções aparentemente simples, como a remoção de pessoas que vivem em áreas de risco, nem sempre são possíveis. Os direitos de cidadania, como o acesso à moradia digna, fazem interface com outros direitos nem sempre confluentes, como, por exemplo, os da terceira geração referentes ao direito de viver em um ambiente não poluído. Por isso, neste texto, abordaremos a questão da gestão dos riscos de desastres ambientais a partir das noções de complexidades e redes heterogêneas de atores $^{7-9}$.

O objetivo desta reflexão é fazer algumas aproximações com a problemática da gestão dos riscos de desastres ambientais, na ótica de pessoas em situações de vulnerabilidade. Para isso, nos apoiaremos nas vertentes críticas das teorias sociais de risco que propõem que, para além da racionalidade implícita nas decisões sobre risco, é preciso entender os processos por meio dos quais os atores em questão dão sentido a comportamentos considerados arriscados ${ }^{10}$.

O texto está organizado em três tópicos, sendo que em cada um deles os conceitos norteadores acima listados serão delineados com maior detalhe. O primeiro tem por objetivo descrever o território em que a pesquisa "Viver em áreas de risco" está sendo desenvolvida e tem como conceito base a noção de vulnerabilidade socioambiental. O segundo tem por foco a rede complexa de atores que performam risco naquele território. O terceiro tópico aborda a gestão dos riscos por parte de pessoas que vivem em áreas de risco e situa a perspectiva psicossocial com que buscamos entender a vida cotidiana no território.

\section{Breve apanhado sobre os objetivos e os procedimentos}

Essas reflexões derivam das etapas iniciais da pesquisa "Viver em área de risco", que vem sendo apoiada pelo CNPq na modalidade de bolsa produtividade, e que tem por base teórica as correntes críticas da psicologia social ${ }^{11-13}$. A fase preliminar da pesquisa, iniciada em 2012, foi dedicada à familiarização com o histórico da defesa civil brasileira e sua estrutura atual decorrente da promulgação da Lei Federal 12.608, de 10 de abril de 2012, que institui a Política Nacional de Proteção e Defesa Civil. Essa fase possibilitou entender o mapeamento de áreas de risco no município de São Paulo e levou à definição do distrito que seria foco da pesquisa - o Jardim Ângela, situado na região sul da capital paulista. No ano de 2013 foram feitas aproximações com os diversos atores envolvidos na questão da gestão de risco nesse território. Para viabilizar a pesquisa, foi fundamental a participação no Fórum em Defesa da Vida, que se 
reúne mensalmente na Sociedade Santos Mártires (SSM), vinculado à paróquia de mesmo nome. Em 2013, a SSM comemorou 25 anos de atividades voltadas à segurança, aos direitos das crianças e dos adolescentes e das mulheres vítimas de violência. Participam do fórum moradores, lideranças locais, gestores e técnicos de serviços públicos, promotores do Ministério Público, assessores da Subprefeitura de M'Boi Mirim, pesquisadores da USP, UNIFESP, PUCSP e FGVSP, sendo, dessa maneira, contexto importante para entender as diversas dimensões da problemática dos riscos ambientais e outros, que a população do distrito enfrenta cotidianamente. As informações que subsidiam a discussão que segue derivam, portanto, em grande parte, dos contatos propiciados pela participação no fórum e em outras atividades da SSM. Vale destacar que a perspectiva ético-política de condução de pesquisas que adotamos ${ }^{14}$ parte da premissa da coconstrução de resultados que implica oferecer contrapartidas que extrapolam os objetivos específicos de pesquisa. Assim, ao perguntarmos aos responsáveis pela SSM em que poderíamos ser úteis, durante o percurso da pesquisa, surgiu a demanda de sistematizar a história da Sociedade Santos Mártires, por meio de análise documental e de entrevistas com informantes por eles indicados. Consequentemente, algumas das informações que serão discutidas neste texto decorrem dessas entrevistas e documentos. Outras, são frutos das muitas conversas que tivemos nesse percurso ainda inicial da pesquisa que visa entender os sentidos do risco para pessoas que, conforme apresentaremos a seguir, constam do mapeamento realizado pela Prefeitura de São Paulo, entre 2009 e 2010, e que moram em áreas consideradas de risco para escorregamentos e/ou inundações. Finalmente, nos apoiamos também em relatos sobre desastres ocorridos em 2013, assim como em matérias de jornal, incluindo algumas localizadas no acervo histórico do jornal $O$ Estado de S. Paulo.

\section{Resultados}

\section{O Jardim Ângela: sua paisagem, sua história}

Os distritos do Jardim Ângela e do Jardim São Luís integram a Subprefeitura de M'Boi Mirim. Essa região foi um dos locais que abrigou a mão de obra das fábricas que se instalaram nas imediações da marginal do rio Pinheiros.

A história do Jardim Ângela está territorialmente associada à de Santo Amaro, cuja colo- nização, incluindo a região do Jardim Ângela, data do século XVII. Em 1832, Santo Amaro foi elevada à categoria de vila, com vocação marcadamente agrícola. Essa vocação foi reconfigurada em dois momentos distintos ${ }^{15}$. O primeiro data de 1889 e decorre da construção da represa Guarapiranga pela São Paulo Tramway, Light and Power, a Light. Em 1928, por solicitação da então Repartição de Águas e Esgoto (RAE), a represa ganhou outra função, a de abastecimento de água para a cidade de São Paulo. A responsabilidade pela manutenção das condições de saneamento da água permaneceu com a Light, embora esta não tivesse jurisdição sobre os terrenos que margeavam a represa, pois tinha apenas adquirido os terrenos da área de inundação.

Nem a Light nem a RAE previram os problemas que viriam com o processo de urbanização da margem esquerda da represa. A margem direita havia sido destinada ao lazer, por meio da implantação do Projeto Interlagos, que previa a construção de um balneário, de um hotel cinco estrelas, do autódromo e de uma cidade satélite nos moldes das "Garden Cities" inglesas. Essa vocação para o lazer foi uma das justificativas para que, em 1935, Santo Amaro fosse anexada à capital.

O segundo momento de reconfiguração da região decorre das primeiras legislações de proteção dos mananciais, aprovadas na década de 1970 e que vão colocar em contraposição a política ambiental de preservação dos mananciais e o processo de expansão urbana. As legislações iniciais eram muito restritivas ${ }^{16}$ e não conseguiram reter a expansão urbana por não estimular formas de ocupação compatíveis com a preservação ambiental. Assim, os proprietários de grandes glebas, vendo-se impedidos de potencializar os índices construtivos, entregaram suas propriedades a loteadores clandestinos, iniciando um comércio ilegal de terras dentro de áreas protegidas, parceladas em lotes mínimos. Aliado a isso, a falta de políticas de habitação, para a população de baixa renda no município, propiciou o deslocamento de grandes contingentes de população para essas áreas.

Atualmente, o Jardim Ângela abarca uma região de $4.638 \mathrm{~km} 2$, onde vivem 295.434 pessoas. Segundo dados do mais recente Mapa da Exclusão/Inclusão Social do Município de São Paulo ${ }^{17}$, publicado em 2013, o Jardim Ângela ocupa o quarto lugar entre os distritos com maior exclusão na capital (-0,92 em uma escala de -1 a 1$)$. Como exemplo do abandono em que vivem seus moradores, há no distrito 31,29\% de domicílios precários subnormais; $21,14 \%$ não têm acesso a 
esgoto e o tempo médio de viagem entre domicílio e local de trabalho é de 56,18 minutos.

Nada mais apropriado, portanto, para entender as vivências da população nesse território, do que o conceito de vulnerabilidade socioambiental. Esse conceito possibilita traduzir os fenômenos de sobreposição espacial e interação entre problemas e riscos sociais e ambientais, sendo adequado para analisar o crescente entrelaçamento entre as dimensões sociais e ambientais da urbanização $o^{4}$. A definição de vulnerabilidade socioambiental combina duas séries de fatores: 1) processos sociais relacionados à precariedade das condições de vida e proteção social que tornam certos grupos, principalmente entre os mais pobres, mais vulneráveis aos desastres; e 2) mudanças ambientais resultantes da degradação do meio ambiente que tornam certas áreas mais vulneráveis ${ }^{5}$.

Assim definida, a noção introduz uma ampliação em relação àquela que, desde a década de 1980, adentrou o discurso crítico sobre desastres ambientais $^{18}$. Foi a partir dessa década que analistas críticos da área de desastres passaram a criticar a centralidade técnica da abordagem com foco em perigos e o individualismo da abordagem do risco, principalmente no caso de países pobres. A emergência do conceito de vulnerabilidade nos estudos sobre desastres marca uma mudança na postura que considerava os desastres como eventos causados por fatores externos para uma interpretação mais sociológica, que toma desastres como processos complexos, socialmente construídos.

\section{Sobre áreas de risco}

Somam-se ao quadro de exclusão social as características da região de mananciais na margem esquerda da represa Guarapiranga. Nas geociências $^{19}$ há dois fatores de risco a serem considerados na análise de escorregamentos: a suscetibilidade (maior ou menor propensão para instabilização do solo, decorrente de características geológicas e geomórficas do terreno, somada a valores de precipitação pluviométrica superiores a 200-250mm) e a vulnerabilidade, ou seja, a predisposição de pessoas, construções e outras materialidades serem afetadas por ocasião de um acidente. A vulnerabilidade está obviamente associada ao uso e ocupação do solo.

Ambas as dimensões estão presentes no distrito do Jardim Ângela. Trata-se, portanto, de área com alta probabilidade de ser afetada por riscos de desastres. Segundo a definição adotada nas geociências, risco é a probabilidade $(P)$ de ocorrência de perigo ou ameaça (A) que pode resultar em consequências $(C)$ danosas para pessoas ou bens, em função da vulnerabilidade $(V)$ do meio e que pode ser diminuído por meio de gerenciamento (G) pelo poder público elou comunidade ${ }^{20}$.

Em 2009, a prefeitura paulistana solicitou ao Instituto de Pesquisas Tecnológicas - IPT, a realização de setorização de risco de escorregamentos e solapamento de margens de córregos em áreas de assentamentos urbanos precários. O foco desse levantamento foram 407 áreas de ocupação precária, onde a vulnerabilidade da população era mais alta. Esse levantamento foi realizado de setembro de 2009 a dezembro de 2010. O método de trabalho incluiu as seguintes atividades: Fase 1 - Triagem das áreas com base em reuniões presenciais para apresentação do trabalho pela equipe técnica do IPT e indicação dos locais a serem avaliados; Fase 2 - Vistoria em campo para aquisição de coordenadas GPS e elaboração do plano de sobrevoo; Fase 3 - Sobrevoo de helicóptero para setorização preliminar e quantificação das moradias; Fase 4 - Trabalho de campo para verificar as características das ocupações e o comportamento da água nos terrenos, bem como a presença de sinais de movimentação do solo; e Fase 5 - Elaboração dos resultados com definição das áreas de risco.

O trabalho de mapeamento de riscos por meio de investigações geológicas-geotécnicas de superfície inclui o levantamento dos condicionantes dos processos de instabilização e das características de ocupação da área e sua infraestrutura. Esses dados são inseridos em um gradiente de risco classificado de 1 (risco baixo) a 4 (risco alto). A partir da atribuição dos graus de risco são estabelecidas as formas de intervenção para redução, mitigação ou erradicação dos riscos ${ }^{20}$, entre elas: 1) Soluções estruturais (serviços de limpeza, drenagem, terraplanagem, remoções de moradias etc.) e 2) Soluções não estruturais, políticas urbanas, planos de defesa civil, educação. São ações complexas que envolvem esforços intersetoriais e, portanto, nos levam a mapear os atores que terão de ser ou já estão envolvidos na questão das áreas de risco.

Na subprefeitura de M'Boi Mirim foram mapeadas 50 áreas de riso: 19 no Jardim São Luís e 31 no Jardim Ângela.

\section{As múltiplas faces dos riscos ambientais no Jardim Ângela: apresentando a rede heterogênea de actantes}

Partimos do pressuposto de que riscos ambientais são fenômenos complexos e, no enqua- 
dre da teoria ator-rede ${ }^{7}$, a complexidade é entendida a partir de uma epistemologia que acolhe a multiplicidade. Não se trata meramente da diversidade de olhares ou da diversidade de objetos, mas de coexistência de versões, cada qual performando (enacting) os objetos de maneira distinta. Distinta, porém não incompatível - há sempre espaços para negociação entre versões múltiplas de um objeto, ou de um fenômeno como risco ambiental.

Se há múltiplas possibilidades de performar um objeto, então, necessariamente, há múltiplos atores com agência nesse contexto de práticas. Bruno Latour ${ }^{7}$ os denomina "actantes" - atores que têm agência, seja diretamente, seja por meio da ação de outros, como é o caso dos alertas de desastres. Portanto, não são meramente atores humanos que integram essa rede. No enquadre da teoria ator-rede adota-se uma postura simétrica que não dicotomiza atores humanos e não humanos. Fala-se, portanto, de uma rede heterogênea de materialidades e socialidades, ou, mais precisamente, de materialidades relacionais.

Para John Law e Annemarie $\mathrm{Mol}^{8}$, materialidades e socialidades são produzidas conjuntamente: Quando olhamos para o social estamos também olhando para a produção de materialidades. E quando olhamos para os materiais, estamos testemunhando a produção do social. Ou seja, tanto os materiais como as pessoas são efeitos relacionais; fora de suas interações eles não têm existência; não têm realidade: Máquinas, pessoas, o mundo natural, o divino - são todos efeitos ou produtos ${ }^{8}$.

Ao falar de realidades múltiplas não nos referimos nem a perspectivas coexistentes nem a processos de construção social; falamos de intervenção e performance ${ }^{9}$. Ou seja, a noção de multiplicidade sugere que realidades são feitas e objetivadas (done and enacted) e não meramente observadas. Ao invés de uma diversidade de olhares enquanto permanece intacta, a realidade é manipulada por meio de várias ferramentas no curso de uma diversidade de práticas. Como parte dessas diversas atividades, o objeto em questão varia de um estágio ao seguinte: são versões diversas performadas pelas ferramentas (ou práticas) utilizadas.

Os riscos ambientais no Jardim Ângela incluem uma diversidade de atores que influem direta ou indiretamente na gestão dos riscos na região. Dentre eles, destacamos: a água, as moradias, os serviços públicos, as vias de acesso e os interesses de uma diversidade de representantes de organizações.
A água é certamente o principal motor das controvérsias sobre a gestão dos riscos na região, seja pela importância da represa e dos rios e córregos que a alimentam, seja pelo seu potencial de destruição. São muitos os atores envolvidos nessa questão. De um lado, as políticas de preservação dos mananciais, de responsabilidade da prefeitura de São Paulo/Secretaria do Verde, com as quais pactuam organizações não governamentais (como o Instituto Sócio Ambiental - ISA), que advogam pelas remoções e/ou pelos projetos de urbanização das moradias em favelas e loteamentos irregulares. É nesse contexto que foi instituído o Programa Mananciais. De outro lado, órgãos que teriam por função precípua a manutenção da qualidade das águas da represa por meio de obras de saneamento, como a SABESP, são agentes de poluição dessas mesmas águas. Lideranças comunitárias, entre elas o padre Jaime Crowe, da paróquia Santos Mártires, acusam a SABESP de despejar esgoto sem tratamento na represa:

P. Jaime: Entramos com outra ação civil pública um pouco mais tarde contra a SABESP, que está engavetada até hoje. Isso foi Santos Mártires, CEDHEP e ISA, Instituto Sócio Ambiental, por causa do esgoto despejado na represa. Entrevistador: Este é que está engavetado? P. Jaime: Sim, está engavetado e não sai nada. Entrevistador: É, isso você mencionou no fórum, quanto era, $80 \%$ do esgoto? P. Jaime: Por nossas estatísticas é $90 \%$, mas entramos com uma ação que diz 80\%, para dar uma margem de erro para nós, porque quem assumiu mais isso foi o ISA, que teve condições de fazer, era na época do lançamento de [...] programa dos mananciais, algo ligado a isso.

As moradias têm papel proeminente nessa rede heterogênea, por sua localização em áreas de risco ou de preservação; pela precariedade de algumas dessas construções, e também por colocarem em pauta a questão da falta de políticas urbanas que possam garantir, concomitantemente, o direito de moradia digna e de preservação ambiental. Moradias são materialidades atravessadas por socialidades. Os distritos das regiões Sul do município têm longa história de mobilização pelo direito à moradia, sobretudo durante os anos $1980^{21}$. Foram muitas as histórias que ouvimos de moradores mais antigos.

Dona G., por exemplo, foi uma das paroquianas que ajudaram a criar a comunidade São Sebastião, embrião da atual paróquia Santos Mártires. Ela contou que, certa ocasião, soube que uma das lideranças do bairro vizinho ia invadir um terreno da prefeitura que ficava no bairro onde Dona G. residia. Ela não achou justo. 
$\mathrm{Na}$ entrevista realizada para registrar a história da Sociedade Santos Mártires, ela disse: Eu não aceitei que ela viesse de lá com a turma dela invadir aqui, sendo que nós também tínhamos pessoas carentes que precisavam de um terreno. Assim as duas, após algumas desavenças, sentaram juntas e dividiram os terrenos: Fica tantos para mim e tantos para vocês. Mas Dona G. alerta que não se tratava de uma invasão: Vamos falar em divisão e não em invasão [...]. Vamos lutar com dignidade; não fazer coisa errada; vamos atrás da prefeitura pedir que nos ajudem a formar essas moradias com dignidade.

No embate entre coibir a ocupação desordenada e zelar pelos direitos de cidadania outros atores entram em cena: pelo Estado, a SEHAB; pela prefeitura, a COHAB; e, em defesa dos moradores, o Ministério Público.

A ocupação do território trouxe novas demandas que também foram foco dos movimentos sociais da década de 1980: a instalação de serviços públicos - água, luz, esgoto. Nas primeiras ocupações não havia nada, apenas ruas cobertas de barro - e são muitas as histórias de sapatos enlameados e da necessidade de levar sempre um par limpo para poder apresentar-se no trabalho. Por exemplo, Dona H. chegou à região em 1968. Morava no bairro Santa Lúcia. Não havia casas ao redor; era um deserto. Era muito difícil, mas, segundo ela, era muito bom: ainda não tinha violência; não se ouvia falar de drogas. Conta as dificuldades de transitar pela região. Era preciso ir até o ônibus andando por ruas enlameadas. $O$ dia que estava chovendo a gente ia de sapatinho velho. Meu pai ia com os sapatos [limpos] na mão. Quando chegava lá no ônibus, a gente calçava e ele trazia de volta os sapatos cheios de barro.

A falta total de benfeitorias gerava cenários propícios para candidatos a cargos públicos fazerem lá suas campanhas. As lideranças locais, sobretudo as mulheres, se organizavam para pressionar o governo municipal, para que instalasse redes de água, luz e asfalto. Organizavam ônibus para ir até a prefeitura; incomodavam. Mas também proporcionavam boas oportunidades para que candidatos a cargos públicos fizessem promessas, algumas das quais cumpridas. Foi o caso de Paulo Maluf, na década de 1970. Dona G. conta que achou bom quando ouviu Maluf dizer quando for prefeito, com 30 dias eu coloco água. Por isso ela votou nele. E de fato Maluf cumpriu a promessa e, segundo ela, não cobrou nada, não cobrou cavalete. Foi de graça para todo mundo. Não que ela fosse malufista, pois em suas palavras, não tenho partido [...] o meu partido é o ho- mem que faz... estou do lado do trabalhador, estou do lado da luta, estou do lado da Igreja.

E assim, é necessário também incluir nessa rede heterogênea os interesses específicos de certos atores. São muitos e variados e, aos poucos, começamos a entender como se fazem presentes e como afetam a percepção do risco, assim como dos direitos a não viver com riscos. Vale lembrar que o Jardim Ângela foi berço do Primeiro Comando da Capital, o PCC e já foi considerada a região mais violenta do planeta: Crise após crise econômica, em 1995 a violência atingiu seu pico e o Jardim Ângela, o fundo do poço. Os índices de assassinatos dispararam para 110 casos por 100 mil habitantes. Em 1996, a região foi apontada pela Organização das Nações Unidas (ONU) como a mais violenta do mundo, notícia que correu os quatro cantos do planeta $^{22 .}$

Os relatos das pessoas que viviam na região à época são contundentes. Por exemplo, M. foi diretora de creche no Riviera, a região em que atuava o Cabo Bruno. Era comum eles matarem e amarrarem os corpos de cabeça para baixo nas árvores. Foram muitas as histórias que ela contou na entrevista realizada para documentar a história da Sociedade Santos Mártires. Por exemplo, havia crianças da creche que pediam lápis vermelho para desenhar e quando perguntavam a elas por que queriam essa cor, diziam que era para pintar o sangue que pingava do corpo de seus pais, irmão, mães.

Atualmente, há consenso de que a situação melhorou, e parte desse esforço se deve à corajosa atuação das paróquias da Igreja Católica, sobretudo na figura do padre Jaime Crowe. Ao reassumir a paróquia Santos Mártires após breve ausência, padre Jaime encontrou a situação ainda pior. Nas palavras dele: Quando voltamos, em julho de 1996, a situação estava cada vez pior, e acho que, como padre, a gente fica envolvido nessas situações, a gente pode dizer que era deprimente, porque saíamos nas ruas e encontrávamos corpos; aí ia no cemitério, encontrava os corpos. Bom, um fato que eu lembro, talvez, valha a pena contar: Eu fui ao cemitério São Luís para enterrar um corpo. Foi num sábado de manhã, e tinham seis enterros $e$, dos seis, cinco deles eram assassinatos. E, lógico, quando um padre vai ao cemitério um ou outro escuta o padre rezando, e chamam o padre para benzer. Então, são as coisas assim que marcavam muito a vida da região na época.

Padre Jaime dizia para todos: não basta a gente ficar enterrando os corpos, nós temos que fazer alguma coisa, pois, enterrando os corpos e fazendo apenas a missa de sétimo dia, temos que fazer algo 
para diminuir isso. Foi assim que, em uma reunião no Centro de Direitos Humanos e Educação Popular de Campo Limpo, em agosto de 1996, surgiu a ideia de fazer uma caminhada pela rua; $\mathrm{e}$ escolheram para isso, o dia 2 de novembro.

Dia de Finados e a chegada seria o cemitério de São Luís, usando a bandeira pela Vida e pela Paz. E daí, nós começamos a mobilizar em torno disso, a reação era muito diversificada, pois muita gente falava que era arriscado, era perigoso, que não era bom colocar o nome na rua, era perigoso botar o povo na rua. Mas a gente usava o argumento: 'enquanto nós recuamos mais espaço nós estamos dando para o crime.' A primeira caminhada estava marcada para uma saída daqui e uma saída de CEDHEP e íamos nos encontrar na metade do caminho para o cemitério, encontrar juntos, e já tínhamos providenciado o som, um caminhão de som e tudo. (Padre) Eduardo e eu já estávamos na rua umas sete e meia, e eu falei pra ele: 'Eduardo acho que só iremos nós dois' (risos). Então, acho que quando foi dez pras oito, choveu gente de todos os lados, e acho que saímos daqui com umas mil pessoas. E foi juntando gente pelo caminho e quando chegamos ao São Luiz, com mais ou menos umas cinco mil pessoas (entrevista com P. Jaime, 17/06/2013).

Dessa caminhada surgiu o Fórum em Defesa da Vida, uma articulação da sociedade civil organizada pela superação da violência na região, contando com a participação dos diretores das escolas, sociedades amigos de bairro e o poder público.

Exclusão, injustiça, falta de infraestrutura, violência. Portanto, não poderiam faltar nessa rede heterogênea atores políticos de vários matizes. A mais recente caminhada Pela Vida, Pela Paz, realizada em 2 de novembro de 2013, contou com a presença de integrantes da Diocese, das paróquias locais, do subprefeito e de seu chefe de Gabinete, de vereadores e candidatos a vereador, assim como da polícia comunitária. E as narrativas sobre eventos relacionados ao Jardim Ângela, conforme já apontado, sempre fazem referência a políticos. Vale apontar que a fama do Jardim Ângela não se deve apenas à violência; a região foi berço de muitas iniciativas importantes, algumas das quais se tornaram políticas públicas, entre elas a experiência inovadora do programa Redescobrindo o Adolescente na Comunidade (RAC), que introduziu a estratégia de medidas socioeducativas em meio aberto, e da Casa Sofia, de apoio a mulheres que sofrem violência doméstica.

Sendo tantos os atores, a formação de parcerias se torna fundamental. Essa possibilidade de agregar múltiplos atores e interesses igualmente diversos foi testada em instigante estudo sobre a avaliação do risco de transmissão de esquistossomose e outras doenças infecciosas e parasitárias de veiculação hídrica no município de Guapimirim, Rio de Janeiro ${ }^{23}$. Para isso, os membros da equipe se apoiaram na proposta de Silvio Funtowicz e Jerome Ravetz ${ }^{24}$ que propõem, para enfrentamento das questões complexas da atualidade, ... a ampliação dos grupos e saberes relacionados ao empreendimento científico, através da formação de 'comunidades ampliadas de pares', que admitam todos os setores (populares, públicos ou privados), envolvidos na questão ${ }^{24}$.

\section{Querer sair, querer ficar: entendendo a gestão dos riscos na perspectiva das pessoas em situação de vulnerabilidade socioambiental}

A gestão dos riscos por parte de pessoas que moram em áreas de risco é tradicionalmente abordada na psicologia social a partir da noção (polissêmica) de percepção de risco ${ }^{25}$. Mas, de maneira geral, as diversas abordagens sobre o tema sofrem de um viés individualista, como aponta Tim Rhodes ${ }^{10}$, para quem há três vertentes principais de teorias psicossociais sobre percepção de riscos. A primeira engloba as teorias de "racionalidade única", de cunho mais cognitivista, que partem do pressuposto de que os cálculos e avaliações de aceitabilidade e suscetibilidade aos riscos estão enraizados em uma única racionalidade a respeito do que é saudável ou danoso. A segunda vertente integra as teorias de "racionalidade situada", que levam em consideração o contexto e propõem que a racionalidade individual depende da situação. Porém, as práticas e comportamentos de risco continuam a ser consideradas como produto de decisões racionais baseadas em custos e benefícios associados com a situação específica. Em contraste, a terceira vertente inclui as teorias da "ação social”, associadas às teorizações de Mary Douglas ${ }^{26}$, que consideram que ações relacionadas a riscos são frequentemente produtos de uma habituação socializada. São fenômenos socialmente organizados.

Essa reconfiguração da noção de percepção de risco está sustentada em dois pressupostos: 1) é necessário entender o significado de comportamentos e práticas considerados arriscados; 2) é preciso também entender os processos por meio dos quais os atores em questão dão sentido a comportamentos considerados arriscados. É particularmente importante entender esses sentidos no 
contexto de outros riscos, de custos e benefícios relacionados a uma prática associada a riscos. Referindo-se aos usuários de drogas, Rhodes ${ }^{10}$ afirma: As percepções de riscos do HIV para usuários de drogas fazem parte de uma hierarquia de "prioridades de riscos" associados a injetar a droga. Colocar a percepção de riscos no contexto de hierarquias de riscos é de fundamental importância para entender por que as pessoas constroem suas moradias em áreas de risco, assim como suas ambivalências quanto a querer sair e querer ficar nelas.

Embora ainda estejamos nas etapas iniciais da pesquisa "Viver em áreas de risco", as entrevistas, conversas, matérias de jornais e revisão bibliográfica sugerem que, para entender a ambivalência entre querer ficar e querer sair de áreas de risco, alguns temas se fazem presentes, entre eles: as razões que levam a morar em áreas de risco; a questão do preconceito, que leva à invisibilidade dos direitos de cidadania; a importância do lugar; a ameaça distante; e a incerteza sobre o futuro.

\section{Quem mora em áreas de risco}

A falta de políticas urbanas e a dinâmica de exclusão das populações mais pobres é tema amplamente abordado entre urbanistas ${ }^{27,28}$. Há muitas histórias de ocupação de terrenos públicos com eventual apoio da prefeitura para regularização de posse e melhorias urbanísticas. Mas há outras histórias que, denominadas genericamente como "invasões", colocam em ação não apenas movimentos sociais voltados ao direito de moradia como também grileiros e diversas formas ilegais de apropriação de terras para fins de comercialização. O caso da Fazenda Itupu, hoje Parque Ecológico Guarapiranga, é um desses eventos que merecem estudos mais aprofundados, pois, apesar de ser amplamente citado como exemplo dos movimentos da década de 1980, muitas dúvidas pairam a seu respeito.

Uma das versões, constante dos jornais da época, é de que a sua ocupação foi articulada pelo $\mathrm{PCdoB}$, com o apoio da Igreja Católica: $O$ governo, com base em informações colhidas no local, tem provas que a invasão da Fazenda Itupu foi incitada com o apoio da "ala progressista" da Igreja e de elementos do Partido Comunista do Brasil $P C$ do $B^{29}$.

Certamente a Igreja foi chamada a atuar. Em matéria publicada no dia 10 de setembro de $1981^{30}$ consta que: O Bispo de Itapecerica da Serra, d. Fernando Penteado esteve, por volta das 14 h30, na Fazenda Itupu para "sentir a situação das famílias” [...] D. Fernando manifestou esperança de que seja criado um organismo mediador para encontrar uma solução "que dê a este povo um teto onde morar”. Mas paira a dúvida sobre esse evento. Por exemplo, muito emocionada, Dona M. contou: Comprei de quem não era dono. Corretores lotearam e nós compramos. Mas apareceu o dono, que não morava no Brasil. Era época do Maluf; do Reinaldo de Barros. Reinaldo falou que não comprava o terreno e acabou morrendo gente. Teve gente que enfartou porque perdeu tudo que tinha e viu a máquina passando, a polícia chegando e batendo.

Atualmente, as remoções não são tão truculentas quanto na década de 1980, mas mesmo assim as dificuldades são muitas. A proteção dos mananciais tornou-se imprescindível como forma de garantir água em quantidade e qualidade para o abastecimento da população, sendo as represas Billings e Guarapiranga fundamentais nesse processo. De modo a reverter a longa história de abandono pela gestão municipal, a prefeitura lançou, em 1996, o Programa Guarapiranga, reconfigurado em 2005 como Programa Mananciais, que está atualmente em sua terceira fase. O programa prevê a canalização de córregos, drenagem, implantação de rede de água e esgoto, regularização fundiária e instalação de equipamentos urbanos, como parques e praças.

Isso requer remoção de muitas moradias e realocação da população. A contrapartida do governo é pagar uma bolsa aluguel de $\mathrm{R} \$ 400,00$. Teoricamente, essas pessoas seriam realocadas em moradias populares. Mas sua construção ainda nem foi iniciada. Há, assim, insegurança sobre a continuidade desse pagamento. E há também dificuldade de encontrar outra moradia por esse aluguel. Durante a reunião do Fórum em Defesa da Vida, realizada na paróquia Santos Mártires, em junho de 2013, houve uma fala contundente de uma moradora do Jardim Capela, área em que estão sendo feitas remoções. Ela contou que comprou sua casa há mais de 20 anos e que nunca soube que se tratava de área de proteção ambiental. Agora, receberá três meses de aluguel social e terá de sair da casa. Além das dificuldades de encontrar outro imóvel para alugar e de não poder comprar outra casa, tem dois cachorros grandes, o que dificulta alugar alguma coisa.

\section{A dupla exclusão: viver entre riscos e preconceitos}

A associação entre processos de exclusão, moradias precárias e preconceito vem sendo discutida em várias pesquisas. Por exemplo, de modo a entender os comportamentos de moradores 
em áreas de deslizamento em Blumenau, Rafaela Vieira ${ }^{31}$ realizou 30 entrevistas, 27 delas com moradores de áreas de alta e moderada suscetibilidade a deslizamento. De maneira geral, a população residente na área estudada tem vergonha de dizer onde mora. Uma das entrevistadas nesta pesquisa, M. de O. afirma: Lá fora pra vocês, pra nós também porque a gente mora aqui, mas lá fora as pessoas [...] vêm até no CELPE16. Pra cá eles não entram, porque têm medo, porque dizem que aqui só tem bandido. O comentário lá fora é isso. E, como lembra A. T.: Lá fora, até fazer a ficha cadastral, se você diz [referiu-se a dizer que mora na Rua Araranguá], tem até quem faz restrições. Fazem restrição sim, porque isso aqui é uma rua de marginal, mas não é nada disso.

Falas semelhantes foram comuns em nossos contatos com os moradores do Jardim Ângela. Trata-se de uma dupla exclusão. Primeiro, por viver no Jardim Ângela, região considerada perigosa, mesmo com a diminuição dos índices de violência. Nas entrevistas realizadas por solicitação da Sociedade Santos Mártires foram relatadas muitas histórias sobre dificuldade de conseguir emprego quando, ao fazer o cadastro, é revelado o endereço. Mas há também a exclusão intradistrito, entre os que moram em ruas urbanizadas e aqueles que habitam os "becos e vilas". Na escola, quando chove, os colegas comentam em tom jocoso: corra para casa para salvar a televisão. E há relatos de professores sobre crianças que deixam de ir à escola por não poderem tomar banho.

\section{A importância do lugar}

$\mathrm{Na}$ pesquisa de Vieira, acima citada, a imagem negativa da região estudada relaciona-se principalmente à falta de infraestrutura e às brigas entre vizinhos. As enchentes e enxurradas foram citadas por apenas 4 dos 30 entrevistados, não sendo abordados os deslizamentos. Para a autora, de modo a compreender o limiar de intolerância em relação ao local de moradia das pessoas, é preciso considerar o significado do lugar. Afirma que: Há um compromisso com o lugar, feito em termos de investimento de capital, através da criação de um senso de afinidade ou identidade com ele. Sendo assim, o abandono completo do lugar raramente acontece. Normalmente é mais provável reduzir o risco mudando-se o uso do solo, ou a forma de adaptação, do que mudando de lugar.

Lugar é uma noção amplamente utilizada pelas disciplinas que têm as formas de ocupação do espaço por foco. Inclui-se aí a geografia onde tem havido um rico debate com especial atenção aos fluxos de pessoas e materiais nos e entre os espaços. Na extensa revisão sobre o tema, Phil Hubbard e Rob Kitchin ${ }^{32}$ afirmam que, para muitos geógrafos, o lugar representa um tipo peculiar de espaço [...], que é definido e construído em termos das experiencias vividas das pessoas. Como tal, os lugares são vistos como fundamentais na expressão de um senso de pertença para aqueles que nele habitam, e são vistos como provedores de um lócus de identidade.

São muitos os exemplos dessa resistência a deixar o lugar, mesmo quando a possibilidade de desastre é conhecida. Em março de 2013, o jornal $O$ Estado de S. Paulo ${ }^{33}$ publicou uma matéria sobre uma pequena comunidade que se recusava a sair de uma área de risco em Cubatão, na descida da Serra do Mar em direção a Santos, região bastante suscetível a deslizamentos. Tratase de bairro conhecido como Cota 400, no qual se estabeleceram os operários que, na década de 1950, construíram a Via Anchieta. A maior parte da população que ali residia foi removida pela prefeitura de Cubatão por ser esta uma área de risco. Contudo, oito famílias teimaram em ficar e continuam ali por terem entrado na justiça contra as remoções. Disse um deles: Meu pai morou aqui por mais de 50 anos, isso aqui é meu. Não vou sair daqui para morar em um "apartamentinho" lá no mangue de Cubatão, prefiro ficar aqui.

\section{A ameaça distante}

Como alguns desastres são raros, e até mesmo incertos, a ameaça é muitas vezes considerada distante. Há um estudo clássico ${ }^{34}$, publicado em 1987, sobre a vida em áreas de risco que ilustra essa questão. Trata-se de estudo sobre contaminação da água com TCE (trichloroethylene) em uma comunidade rural no estado de Nova York. Apesar da informação fornecida pelas agências de governo e da realização de reuniões com a comunidade, havia pouca preocupação com a possibilidade de contaminação entre os moradores. Dentre as razões apontadas pelas autoras, vale destacar que o TCE não tem gosto nem cheiro e que não havia manifestações aparentes de doenças a ele associadas. Os riscos eram apenas probabilísticos. Além do mais, muitos residentes trabalhavam em locais que usavam o TCE como desengordurante; estavam familiarizados com o produto. E há de acrescer também que os responsáveis pela contaminação da água eram membros da comunidade.

Em suma, familiaridade e incerteza quanto à possibilidade de ocorrência de desastres é fator 
importante na hierarquização de riscos e, consequentemente, de sentidos que são atribuídos aos eventos, como chuvas intensas. Exemplo disso são as moradias construídas em terrenos próximos a córregos. Por exemplo, em fevereiro de 2013 as chuvas típicas de verão causaram bastantes estragos na Serra do Mar. Uma dessas ocorrências abalou uma linda cidade praiana: Boissucanga, no litoral paulista. Escorregamentos e inundações afetaram 1.500 famílias no município - 400 casas só em Boissucanga. Mas foi a morte de uma garotinha de 11 anos que teve maior repercussão.

No caso relatado, tratava-se de uma família de classe média. A casa era bonita e localizada em um local paradisíaco, à beira de um rio - desses rios que na estiagem correm mansos, mas nas chuvas tornam-se torrenciais. A família já havia sido alertada pela Defesa Civil que se tratava de área de risco e, nas chuvas, tomava algumas precauções. Nesse dia fatídico, como já haviam sido alertados de que as chuvas extrapolavam os limites de segurança (índices pluviométricos que variam de 80 a $120 \mathrm{~mm}$ de chuvas acumuladas em três dias), a mãe solicitou ajuda da Defesa Civil para retirá-las do local e levou sua filha para o andar de cima. Em um dado momento, desceu para pegar um lanche e, ao olhar pela janela, viu uma onda gigantesca se aproximando. A onda levou casa, carros, móveis e, claro, mãe e filha. A mãe se salvou. A criança morreu. Não foi apenas o volume de água decorrente das chuvas. Árvores haviam caído mais acima e represado o rio que, quando quebrou a barreira, formou a onda gigantesca - um evento raro e imprevisível.

\section{A incerteza sobre o futuro}

Incerteza é a falta de conhecimento a priori sobre uma determinada situação. No contexto da gestão de riscos, é termo utilizado tradicionalmente em oposição à possibilidade de cálculo e de estimativa de probabilidade de ocorrência de um evento. Para alguns autores, como Ulrich Beck $^{35}$, esta seria a condição típica da modernidade tardia, que tem como característica a multiplicação das incertezas manufaturadas e, nesse sentido, aplica-se à imprevisibilidade de ocorrência de eventos como desastres ambientais. Porém, a noção de incerteza aplica-se também aos acontecimentos da vida cotidiana para os quais o futuro não pode ser previsto, tendo em vista a falta de informações que possam gerar expectativas sobre determinadas ações.

Também na hierarquia de riscos há a questão da incerteza sobre o futuro, especialmente no caso em que uma solução possível para a gestão dos riscos é a remoção. Na reunião do Fórum em Defesa da Vida, realizada em 5 de julho de 2013, Dona Z. falou de sua situação. Ela mora em uma área do Jardim Capela, onde estão ocorrendo remoções. Contou que três irmãos seus que moravam em áreas da prefeitura já foram removidos. Mas ela mora na parte que é propriedade privada, e não sabe o que vai acontecer. Mora lá desde 1977 e no terreno há três casas: da mãe, do sogro e a dela. Morou sempre lá. Conheceu o marido no bairro, casou, comprou o terreno, construiu. Até agora, ninguém falou nada sobre se as casas da parte que está em terreno privado vão ser desapropriadas.

E no caso de remoções, assim como no desalojamento em decorrência de desastres, a espera por abrigo pode ser longa. Norma Valêncio ${ }^{36}$, por solicitação do Conselho Federal de Psicologia (CFP), realizou um estudo cujo objetivo era descrever e analisar as dimensões objetivas e simbólicas que afetavam grupos desabrigados e desalojados em desastres ocorridos no Brasil. A pesquisa de campo foi feita em seis municípios: Ilhota, SC; Teresópolis e Petrópolis, RJ; Barreiros, PE; Jaboatão dos Guararapes, PE; e União dos Palmares, AL. Os casos foram selecionados não apenas por se destacarem, na imprensa e no discurso oficial, como ocorrências de grande vulto, mas porque apresentavam indícios de que os grupos mais afetados estavam em situação de abandono. São perdas cumulativas, de bens, quando não de vidas, que muitas vezes empurram as pessoas para níveis cada vez maiores de vulnerabilidade.

\section{Discussão}

São muitos os atores nessas redes heterogêneas e, portanto, são muitas as conexões e versões sobre o tema "viver em áreas de risco". Alguns dos atores humanos fazem interlocuções com não humanos, caracterizando a geomorfologia, monitorando os índices pluviométricos, registrando os sinais de movimentação do solo. É o caso dos engenheiros, geólogos, geógrafos e operadores da Defesa Civil. Outros buscam soluções estabelecendo diretrizes para questões urbanas, incluindo as formas de ocupação do solo: urbanistas e ambientalistas, por exemplo. Uns são chamados para atuar na comunicação de riscos e na educação para prevenção de riscos; outros são chamados para dar apoio quando ocorrem desastres. Tensões são deflagradas quando distintas noções de riscos e vulnerabilidades são performadas: promotores zelam por direitos no caso das vul- 
nerabilidades civis; operadores da Defesa Civil zelam pela segurança daqueles que estão vulneráveis por exposição a riscos. Organizações Civis, acadêmicos, agentes comunitários protestam, levantam indicadores de vulnerabilidade socioeconômica. Todos se pautam nos direitos constitucionais. E muitas metas louváveis ficam apenas nos discursos.

É um campo de pesquisa transdisciplinar. Porém, ao analisar dados sobre grupos de pesquisa, publicação de artigos científicos e de teses/dissertações, Carlos Freitas ${ }^{37}$ concluiu que as ciências sociais respondem por uma parcela pequena da produção sobre problemas ambientais em seu cruzamento com a saúde coletiva. Essa conclusão causa estranhamento, tendo em vista que, conforme apontado na introdução deste texto, as correntes mais atuais de análise de desastres incorporaram noções como vulnerabilidade e resiliência, que necessariamente impõem um olhar sobre as dimensões históricas, sociais e culturais que se fazem presentes na vivência cotidiana de riscos ambientais.

Nesse contexto propomos que a psicologia social crítica tem muito a contribuir. Partindo de uma perspectiva ontológica de realidades múltiplas, possibilita entender as diferentes maneiras

\section{Agradecimentos}

A pesquisa "Viver em áreas de risco" conta com o apoio do CNPq por meio de bolsa produtividade. Agradecemos as diversas pessoas que se dispuseram a conversar sobre a história e a vida cotidiana no Jardim Ângela, sobretudo o padre Jaime Crowe e a equipe da Sociedade Santos Mártires, que vêm nos dando acolhida para a realização da pesquisa. em que fenômenos como os riscos ambientais são performados em redes heterogêneas de atores. Dando prioridade à compreensão dos processos de produção de sentidos ${ }^{38}$, retoma modos de pesquisar que valorizam os micro lugares da ação cotidiana ${ }^{12,13}$. A partir da valorização da ação local, possibilita reconfigurar a problemática da percepção de riscos, situando-a no enquadre da ação social e das hierarquias de riscos nos contextos da vida cotidiana.

Porém, não se trata de delegar a pesquisadores bem intencionados, a organizações comunitárias ou às ONG esta tarefa de conectar com as pessoas sem seus territórios. É necessário que todos os atores envolvidos assumam esta postura. É importante, sobretudo, que a questão das áreas de risco seja configurada também como problema de saúde pública, não só porque a insalubridade das moradias precárias tem repercussão na saúde das pessoas que lá moram, mas também porque a conexão entre ambiente e saúde, embora historicamente conhecida ${ }^{39}$, fica frequentemente fragilizada pela própria desconexão das políticas setoriais. Portanto, à guisa de conclusão, voltamos a enfatizar que a conexão nessas redes heterogêneas se dá apenas nos micro lugares da vida cotidiana.

\section{Referências}

1. Foucault M. O nascimento da medicina social. In: Machado R, organizador. Microfísica do poder. Rio de Janeiro: Graal; 1982. p. 79-98.

2. Bosher L, Dainty A. Disaster risk reduction and 'buil$t$-in' resilience: towards overreaching principles for construction practices. Disaster 2011; 35(1):1-18.

3. Freitas CM, Ximenes EF. Enchentes e saúde pública: uma questão na literatura científica recente das causas, consequências e respostas para prevenção e mitigação. Cien Saude Colet 2012; 17(6):1601-1615.

4. Alves HPF, Alves CD, Pereira MN, Monteiro AMV. Dinâmicas de urbanização na hiperperiferia da metrópole de São Paulo: análise dos processos de expansão urbana e das situações de vulnerabilidade socioambiental em escala intraurbana. Rev bras estud popul 2010; 27(1):141-159.

5. Freitas CM, Carvalho ML, Ximenes EF, Arraes EF, Gomes JO. Vulnerabilidade socioambiental, redução de riscos de desastres e construção da resiliência - lições do terremoto no Haiti e das chuvas fortes na Região Serrana, Brasil. Cien Saude Colet 2012; 17(6):15771586.

6. Bobbio N. The age of rights. Cambridge: Polity Press; 1996. 
7. Latour B. Reassembling the social: an introduction to Actor-Network-Theory. Oxford: Oxford University Press; 2005.

8. Law J, Mol A. Notes on materiality and sociality. The Sociological Review 1995; 43(2):274-294.

9. Mol A. Políticas ontológicas. Uma palavra e algumas questões. In: Law J, Hassard J, editors. Actor Network Theory and After. Oxford: Balckwell Publisher; 1999. p. 74-89.

10. Rhodes T. Theorizing and researching 'risk': notes on the social relations of risk in heroin users' lifestyle. In: Aggleton P, Davies P, Hart G, editors. AIDS: safety, sexuality and risk. London: Taylor \& Francis; 1995. p. 125-143.

11. Íñiguez L. Nuevos debates, nuevas ideas y nuevas prácticas en la psicología social de la era 'post-construccionista. Athenea Digital 2005; 8.

12. Spink MJP. Pesquisando no cotidiano: recuperando memórias de pesquisa em Psicologia Social. Psicol Soc 2007; 19(1):7-14.

13. Spink PK. O Pesquisador conversador no cotidiano. Psicol Soc 2008; 20(No Esp.):70-77.

14. Spink MJP. A Ética na pesquisa social: da perspectiva prescritiva à interanimação dialógica. Psico 2000; 3(1):7-22.

15. Mendes D, Carvalho MCW. A ocupação da bacia do Guarapiranga: perspectiva histórico-urbanística. In: França E, organizadora. Guarapiranga: recuperação urbana e ambiental no município de São Paulo. São Paulo: M. Carrilho Arquitetos; 2000. p. 39-65.

16. Sales MM, França E, Filardo Júnior AS. Aspectos da Formação da represa e principais transformações. In: França E, organizadora. Guarapiranga: recuperação urbana e ambiental no município de São Paulo. São Paulo: M. Carrilho Arquitetos; 2000. p. 69-113.

17. Sposati A, coordenação. Mapa da Inclusão/Exclusão da Cidade de São Paulo III. São Paulo: CEDESP/PUCSP; 2013.

18. Frerks G, Warner J, Weijs B. The politics of vulnerability and resilience. Ambiente e Sociedade 2011; $\operatorname{xiv}(2): 105-122$.

19. Ogura AT. Mudanças climáticas e gestão de desastres naturais. In: Malaquias, MAV, organizador. Temas de direito urbanístico 6 - áreas de risco. São Paulo: Imprensa Oficial do Estado de São Paulo, Ministério Público do Estado de São Paulo; 2011. p. 37-50.

20. Macedo ES, Canil K, Gramani MF. Instrumentos para a gestão de áreas de risco em assentamentos urbanos precários. In: Malaquias MAV, organizador. Temas de direito urbanístico 6 - áreas de risco. São Paulo: Imprensa Oficial do Estado de São Paulo, Ministério Público do Estado de São Paulo; 2011. p. 121-137.

21. Calderón AI. Participação popular - uma abordagem na lógica da função governativa. São Paulo Perspec 1995; 9(4):29-39.

22. O pacificador do Jardim Ângela. O Estado de S Paulo 2004; 31 out. C6.

23. Soares MS, Silva CLPAC, Barreto MGM, Baptista DF, Borges DA. Solução de problemas em saúde e ambiente: ciência pós-normal e comunidade ampliada de pares em um município brasileiro de pequeno porte. Cien Saude Colet 1998; 3(2):115-123.

24. Funtowitz SO, Ravetz JR. Science for the post-normal age. Futures 1993; (Sep):739-755.
25. Silva FC. Instrumentos de comunicacão de riscos como ferramenta para a diminuição da vulnerabilidade de moradores de assentamentos precários urbanos sob risco de deslizamentos [dissertação]. São Paulo: Instituto de Pesquisas Tecnológicas; 2010.

26. Douglas M. Risk and blame: essays in cultural theory. London: Routledge; 1992.

27. Kowarick L.Viver em risco:sobre a vulnerabilidade socioeconômica e civil. São Paulo: Ed. 34; 2009.

28. Maricato E. As ideias fora do lugar e o lugar fora das ideias: planejamento urbano no Brasil. In: Arantes $\mathrm{O}$, Vainer C, Maricato E, organizadores. A cidade do pensamento único: desmanchando consensos. Petrópolis, RJ: Vozes; 2002. p. 121-192.

29. Igreja e PC sob suspeita. O Estado de S Paulo 1981; 12 set. capa.

30. Invasores garantem que ficam. O Estado de S Paulo 1981. 10 set. p. 21.

31. Vieira R. Um olhar sobre a paisagem e o lugar como expressão do comportamento frente ao risco de deslizamento [tese]. Florianópolis: Universidade Federal de Santa Catarina; 2004.

32. Hubbard P, Kitchin R. Key thinkers on space and place. London: Sage; 2011.

33. Famílias resistem em 'bairro-fantasma' na serra do mar. O Estado de S Paulo 2013; 3 mar. C7.

34. Fitchen JM, Heath JS, Fessenden-Raden J. Risk perception in community context: a case study. In: Johnson $\mathrm{B}$, Covello VI, editors. The social and cultural construction of risk: essays on risk selection and perception. Dordrecht: D. Reidel Publishing Company; 1987. p. 31-54.

35. Beck U. Risk society revisited: theory, politics and research programmes. In: Adam B, Beck U, Loon JV, editors. The risk society and beyond. London: Sage Publications, 2000. p. 211-229.

36. Valencio N, Siena M, Marchezini V. Abandonados nos desastres: uma análise sociológica de dimensões objetivas e simbólicas de afetação de grupos sociais desabrigados e desalojados. Brasília: Conselho Federal de Psicologia; 2011.

37. Freitas CM. Problemas ambientais, saúde coletiva e ciências sociais. Cien Saude Colet 2003; 8(1):137-150.

38. Spink MJP, organizadora. Práticas discursivas e produção de sentidos no cotidiano. Rio de Janeiro: Centro Edelstein de Pesquisas Sociais; 2013.

39. Rosen G. Uma história da saúde pública. 2a ed. São Paulo, Rio de Janeiro: Hucitec, Unesp, Abrasco; 1994.

Artigo apresentado em 09/03/2014

Aprovado em 20/05/2014

Versão final apresentada em 23/05/2014 